\title{
Comparative Evaluation of Antibacterial Efficacy of Four Toothpastes and Mouthwashes against Streptococcus mutans and Lactobacillus: An in vivo Study
}

\author{
1 Jonathan E Sam, ${ }^{2}$ Paulaian Benin, ${ }^{3}$ Ruth H Beaulah, ${ }^{4}$ Gnanaseelan, ${ }^{5}$ Lal Krishna, ${ }^{6}$ Jacob Raja
}

\begin{abstract}
Background: Cariogenic microorganisms are the most important cause for occurrence of dental caries. Dentifrices and mouthwashes containing antimicrobial substances are proven to be effective in the eradication of these pathogens from the oral cavity.
\end{abstract}

Aim: To evaluate the antimicrobial efficacy of fluoride, chlorhexidine $(\mathrm{CHX})$, herbal, and xylitol containing toothpastes and mouthwashes against Streptococcus mutans (S. mutans) and Lactobacillus $(L B)$ in subjects within the age group of 18 to 22 years at time intervals of 1,3 , and 6 months.

Materials and methods: One hundred subjects were randomly divided into four groups. Group I: fluoride, group II: chlorhexidine, group III: herbal, group IV: xylitol and instructed to use toothpastes and mouthwashes containing the specific agents. Salivary samples were collected to evaluate the levels of S. mutans and $L B$ at baseline, 1,3 , and 6 months. Bacterial levels were evaluated using caries risk test (CRT) kit. Data were analyzed using analysis of variance and post hoc test

Results: During intragroup comparison, S. mutans levels in group I showed statistically significant difference among the four time intervals. On intergroup comparison, S. mutans levels after 6 months for groups I, II, III, and IV were 1.12, 1.16, 1.28, and 1.4 respectively.

Conclusion: It can be concluded that fluoride, $\mathrm{CHX}$, and xylitol showed a significant reduction in $S$. mutans and $L B$ count after a time period of 6 months while herbal group did not show a significant reduction in $S$. mutans and $L B$ count at any intervals.

Keywords: Chlorhexidine, Fluoride, Herbal, Lactobacillus, Streptococcus mutans, Xylitol.

How to cite this article: Sam JE, Benin P, Beaulah RH, Gnanaseelan, Krishna L, Raja J. Comparative Evaluation of Antibacterial Efficacy of Four Toothpastes and Mouthwashes against Streptococcus mutans and Lactobacillus: An in vivo Study. J Oper Dent Endod 2016;1(2):60-65.

\footnotetext{
${ }^{1,6}$ Professor and Head, ${ }^{2,4,5}$ Senior Lecturer, ${ }^{3}$ Postgraduate Student

${ }^{1-5}$ Department of Conservative Dentistry and Endodontics Rajas Dental College, Thirunelveli, Tamil Nadu, India

${ }^{6}$ Department of Periodontics, Rajas Dental College, Thirunelveli Tamil Nadu, India

Corresponding Author: Jonathan E Sam, Professor and Head Department of Conservative Dentistry and Endodontics Rajas Dental College, Kavalkinaru, Thirunelveli District, Tamil Nadu India, e-mail: jonathanemil@gmail.com
}

\section{Source of support: Nil}

Conflict of interest: None

\section{INTRODUCTION}

Dental caries is an infectious, microbiological disease of teeth that ends up in the destruction of dental hard tissues. This results from the accumulation of plaque on the surface of teeth. ${ }^{1}$ Streptococcus mutans (S. mutans) and Lactobacillus $(L B)$ are the main pathogens for dental caries that plays a central role in fermenting carbohydrates, resulting in acid production and leading to the demineralization of tooth. ${ }^{2}$

Cariogenic bacteria convert sugars into acids through a glycolytic process called fermentation. If left in contact with the tooth for a prolonged time period, these acids cause demineralization. ${ }^{3}$ This process is dynamic; however, remineralization can also occur if the acid is neutralized and suitable minerals are available in the mouth from saliva and also from preventive aids, such as toothpaste and mouthwash. If sufficient acid is produced over a period of time in the favor of demineralization, caries will progress forming a cavity. ${ }^{4}$

With accurate risk assessment, caries preventive modalities including fluoride, chlorhexidine ( $\mathrm{CHX})$, xylitol, and herbal products can be used efficiently and invasive restorative procedures can be more conservative.

Fluoride is a promising antimicrobial agent in caries prevention. Fluorides are known for their inhibitory effect on growth of microorganisms and for the retardation of plaque growth by lowering their acidogenic potential. ${ }^{5}$ Chlorhexidine is an antimicrobial ingredient in oral health care with substantivity and antimicrobial properties. ${ }^{6}$ Herbal extracts have been successfully used in dentistry for tooth cleaning and as antimicrobial plaque agents. These natural phytochemicals could offer a promising approach in prevention and therapeutic strategies for dental caries. ${ }^{7}$ Xylitol helps in caries prevention by reducing plaque metabolism, bacterial adherence, and by inhibiting enamel demineralization. ${ }^{8}$

The aim of this study was to evaluate the antimicrobial efficacy of fluoride, CHX, herbal, and xylitol containing toothpastes and mouthwashes against $S$. mutans and $L B$ in subjects within the age group of 18 to 22 years at time intervals of 1,3 , and 6 months. 

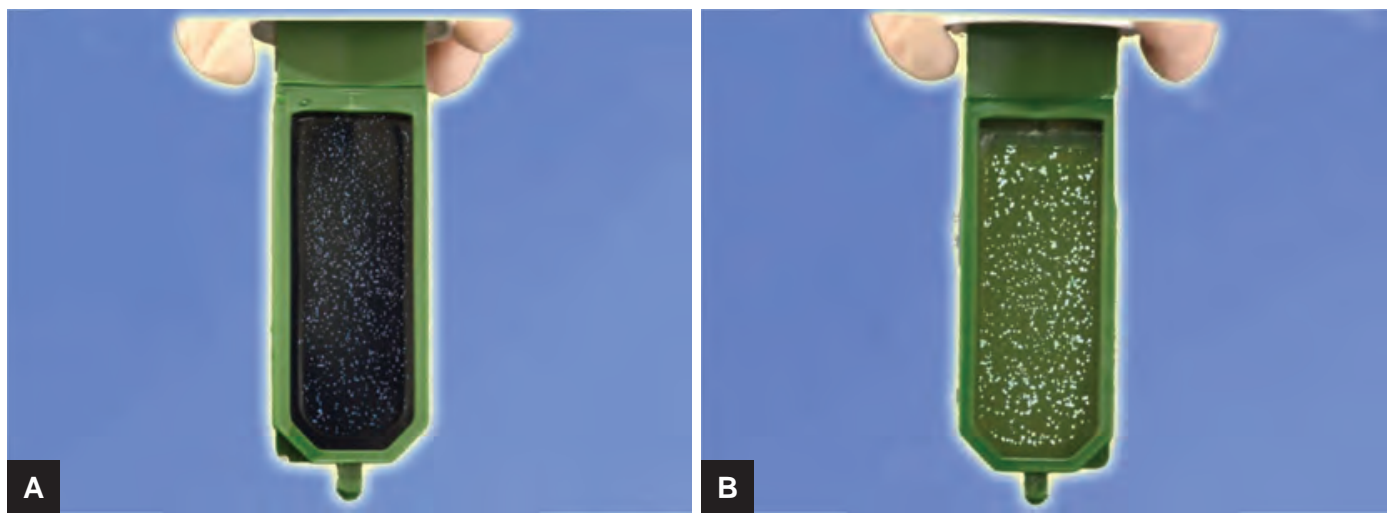

Figs $1 \mathrm{~A}$ and B: (A) Growth of S. mutans; and (B) growth of $L B$

\section{MATERIALS AND METHODS}

\section{Subject Selection}

This in vivo study was conducted among 100 college going students in the age group of 18 to 22 years. They were clinically examined and if any dental caries present were restored with appropriate restorative materials before subjected into different groups. This was confirmed by an expert that there was no caries present in any of the subjects. The procedures were explained to them verbally and a written informed consent was obtained. The study protocol was submitted to institutional research committee and ethical board, and approval was obtained.

The subjects were randomly divided into four groups with 25 subjects $(n=25)$ in each group. Salivary samples were collected from the subjects for microbial count and buffer capacity (BC) evaluation. A simple randomization technique was followed for assigning subjects into their designed groups. The stratified list was provided to the operator who assigned participants in each striatum in sequential order to the treatment group. Baseline values were obtained and were used for follow-up evaluation.

Table 1: Agents used with usage protocol

\begin{tabular}{|c|c|c|c|}
\hline Agents & Toothpaste & Mouthwash & Usage \\
\hline Fluoride & $\begin{array}{l}\text { Colgate (Colgate- } \\
\text { Palmolive } \\
\text { Limited, Mumbai, } \\
\text { India) }\end{array}$ & $\begin{array}{l}\text { Senquel AD } \\
\text { (Dr. Reddys } \\
\text { laboratories, } \\
\text { Hyderabad, India) }\end{array}$ & $\begin{array}{l}\text { Morning } \\
\text { and Night }\end{array}$ \\
\hline Chlorhexidine & $\begin{array}{l}\text { Elgydium } \\
\text { (Laboratoires } \\
\text { Pierre Fabre } \\
\text { Castres, France) }\end{array}$ & $\begin{array}{l}\text { Rexidin [Warren } \\
\text { (Indoco } \\
\text { Remedies Ltd), } \\
\text { New delhi, India] }\end{array}$ & $\begin{array}{l}\text { Morning } \\
\text { and Night }\end{array}$ \\
\hline Herbal & $\begin{array}{l}\text { Himalaya } \\
\text { Complete Care } \\
\text { (Himalaya drug } \\
\text { company, Makali, } \\
\text { Banglore, India) }\end{array}$ & $\begin{array}{l}\text { Hi-Ora (Himalaya } \\
\text { drug company, } \\
\text { Makali, Banglore, } \\
\text { India) }\end{array}$ & $\begin{array}{l}\text { Morning } \\
\text { and Night }\end{array}$ \\
\hline Xylitol & $\begin{array}{l}\text { Spry (Xlear, Inc., } \\
\text { American Fork, } \\
\text { USA) }\end{array}$ & $\begin{array}{l}\text { Spry (Xlear, Inc., } \\
\text { American Fork, } \\
\text { USA) }\end{array}$ & $\begin{array}{l}\text { Morning } \\
\text { and Night }\end{array}$ \\
\hline
\end{tabular}

\section{Evaluation Criteria}

The evaluations were performed before using the study materials after 1, 3, and 6 months.

The subjects were given a paraffin wax and asked to chew for a period of 30 seconds and then to swallow saliva but not the paraffin. Thereafter, the subjects continued to chew the wax and the saliva was collected at 2-minute interval for a total period of 6 minutes in a calibrated beaker. The accumulated saliva was used for subsequent tests. Baseline investigations were performed and added in the investigation chart (Table 1). ${ }^{9}$

The levels of $S$. mutans and $L B$ were evaluated using commercial caries risk test (CRT) kit (Figs 1A and B). The kit comprises a slide with one side coated with a solid selective culture medium (mitis salivarius agar enriched with sucrose) for the cultivation of $S$. mutans while the other side contains Rogosa agar for the cultivation of $L B$. A drop of saliva was pipetted on each surface, one for $S$. mutans and other for $L B$. The agar plates were incubated using an incubator for 48 hours at $37^{\circ} \mathrm{C}$ to allow the growth of the organisms following manufacturer's instructions. Growth density of the bacteria was evaluated under good lighting conditions. Bacterial growth was then scored by comparing with standards expressed in colony forming units (CFUs) provided by the manufacturer (Table 2).

In each group subjects were advised to use toothpaste in the morning and mouthwash at night. All the subjects were given Oral B - soft tooth brush and advised to brush for 3 minutes using Stillman's brushing technique. Likewise subjects were instructed to use the mouthwash holding it in the mouth for 2 minutes and not to rinse with water for 5 minutes thereafter. The same procedure was repeated for all the groups at the intervals of 1,3 , and 6 months. The data obtained at periodical time duration were entered in the evaluation sheet corresponding

Table 2: Scoring criteria for the bacterial colony

\begin{tabular}{ll}
\hline Low & Less than $10^{5} \mathrm{CFUs} / \mathrm{mL}$ \\
High & Greater than $10^{5} \mathrm{CFUs} / \mathrm{mL}$ \\
\hline
\end{tabular}


to the various time intervals. These data were used for statistical analysis.

\section{RESULTS}

Data were analyzed using Statistical Package for the Social Sciences (SPSS) version 20.0. To compare the mean difference between the four groups at four different time intervals, analysis of variance was used. To find out the individual significance, post hoc test with a Bonferroni test for multiple correction was used. For the entire analysis, p-value $<0.05$ was considered significant.

Table 3 and Graphs 1 and 2 show the comparison between levels of $S$. mutans and $L B$ within the study groups at various intervals. Streptococcus mutans values in fluoride group showed statistically significant differences among four time intervals. In CHX and xylitol groups, the mean values were 1.16 and 1.28 , and the p-values were $<0.016$ and $<0.031$ respectively. On comparing the levels of $L B$ within the different study groups at 6 months, the mean was found to be 1.24, 1.28, 1.40, and 1.48 respectively, for fluoride, CHX, herbal, and xylitol groups. Fluoride and CHX groups showed a statistically significant difference among four time intervals. The mean value was 1.28 and $p$-value was $<0.001$ and hence, it was considered to be very highly significant. On comparing herbal and xylitol groups, no statistically significant difference was found at any time intervals.

Table 4 , Graphs 3 and 4 show the intergroup comparison of $S$. mutans and $L B$ levels among different agents at different time periods. The mean difference of $S$. mutans on comparing the baseline values with 3 to 6 months ( 0.4 and 0.56 respectively) in group I was statistically significant on comparing with groups II, III, and IV. For the remaining time intervals no statistically significant difference was

Table 3: Intragroup comparison of $S$. mutans and LB at different time periods

\begin{tabular}{|c|c|c|c|c|c|c|c|c|c|}
\hline \multirow[b]{2}{*}{ Groups } & \multirow[b]{2}{*}{ Parameter } & \multicolumn{4}{|c|}{ S. mutans } & \multicolumn{4}{|c|}{$L B$} \\
\hline & & Mean & $S D$ & $F$ & Sig. & Mean & $S D$ & $F$ & Sig. \\
\hline \multirow[t]{4}{*}{ Fluoride } & Baseline & 1.68 & 0.476 & 7.322 & 0 & 1.72 & 0.458 & 4.305 & 0.007 \\
\hline & 1 Month & 1.48 & 0.51 & & & 1.52 & 0.51 & & \\
\hline & 3 Months & 1.28 & 0.458 & & & 1.44 & 0.507 & & \\
\hline & 6 Months & 1.12 & 0.332 & & & 1.24 & 0.436 & & \\
\hline \multirow[t]{4}{*}{ Chlorhexidine } & Baseline & 1.72 & 0.458 & 7.764 & 0.016 & 1.8 & 0.408 & 5.721 & 0.001 \\
\hline & 1 Month & 1.4 & 0.5 & & & 1.56 & 0.507 & & \\
\hline & 3 Months & 1.24 & 0.436 & & & 1.4 & 0.5 & & \\
\hline & 6 Months & 1.16 & 0.374 & & & 1.28 & 0.458 & & \\
\hline \multirow[t]{4}{*}{ Herbal } & Baseline & 1.76 & 0.436 & 2.434 & 0.07 & 1.76 & 0.436 & 2.4 & 0.073 \\
\hline & 1 Month & 1.64 & 0.49 & & & 1.6 & 0.5 & & \\
\hline & 3 Months & 1.56 & 0.507 & & & 1.52 & 0.51 & & \\
\hline & 6 Months & 1.4 & 0.5 & & & 1.4 & 0.5 & & \\
\hline \multirow[t]{4}{*}{ Xylitol } & Baseline & 1.68 & 0.476 & 0.085 & 0.031 & 1.68 & 0.476 & 0.789 & 0.503 \\
\hline & 1 Month & 1.52 & 0.51 & & & 1.6 & 0.5 & & \\
\hline & 3 Months & 1.4 & 0.5 & & & 1.52 & 0.51 & & \\
\hline & 6 Months & 1.28 & 0.458 & & & 1.48 & 0.51 & & \\
\hline
\end{tabular}

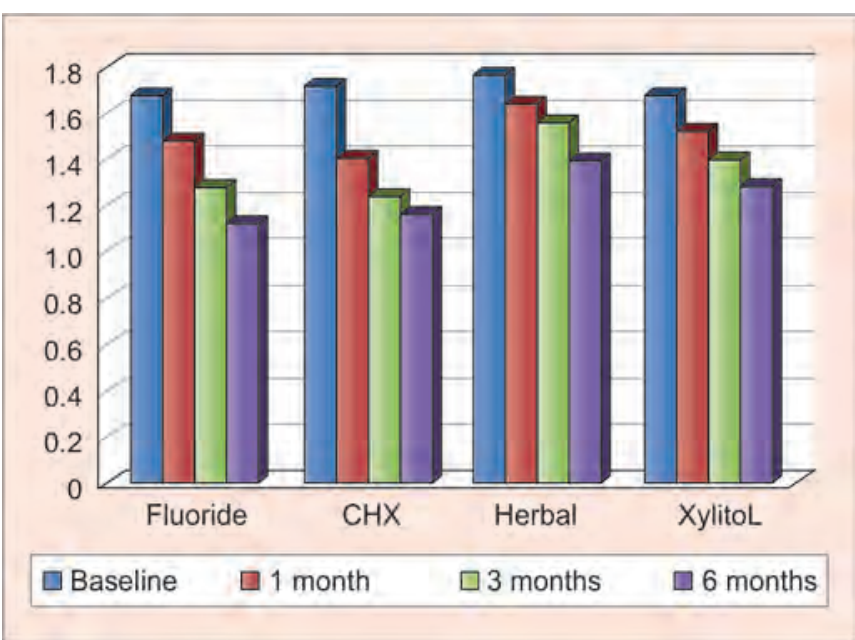

Graph 1: Intragroup comparison of S. mutans at different time periods

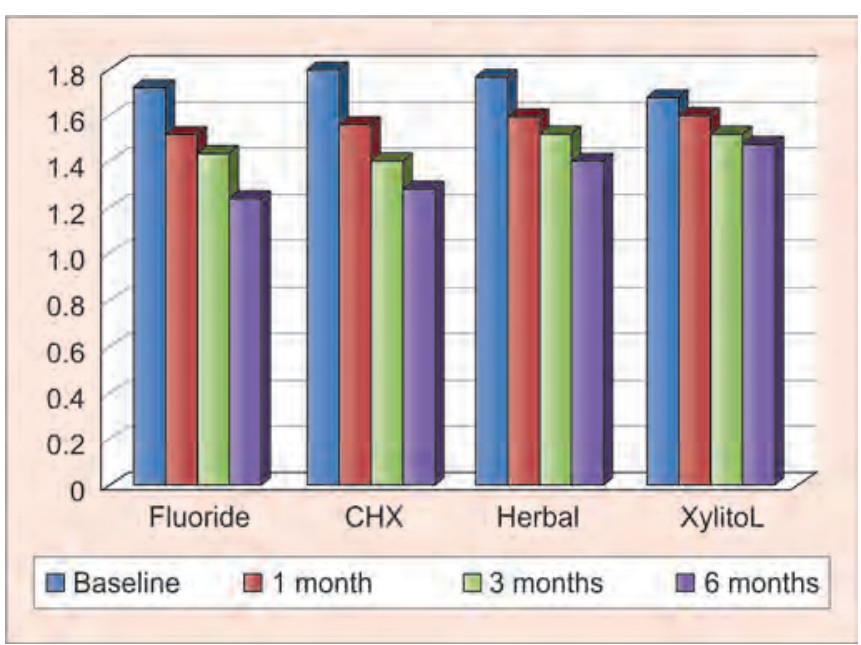

Graph 2: Intragroup comparison of $L B$ at different time periods 
Comparative Evaluation of Antibacterial Efficacy of Four Toothpastes Mouthwashes against S. mutans and Lactobacillus

\begin{tabular}{|c|c|c|c|c|c|c|c|c|c|}
\hline \multirow[b]{2}{*}{ Groups } & \multirow[b]{2}{*}{ Parameter } & \multicolumn{4}{|c|}{ S. mutans } & \multicolumn{4}{|c|}{$L B$} \\
\hline & & Mean & $S D$ & $F$ & Sig. & Mean & $S D$ & $F$ & Sig. \\
\hline \multirow[t]{4}{*}{ Baseline } & Fluoride & 1.68 & 0.476 & 0.172 & 0.915 & 1.72 & 0.458 & 0.336 & 0.799 \\
\hline & Chlorhexidine & 1.72 & 0.458 & & 1.8 & 0.408 & & & \\
\hline & Herbal & 1.76 & 0.436 & & 1.76 & 0.436 & & & \\
\hline & Xylitol & 1.68 & 0.476 & & 1.68 & 0.476 & & & \\
\hline \multirow[t]{4}{*}{1 Month } & Fluoride & 1.48 & 0.51 & 0.99 & 0.401 & 1.52 & 0.51 & 0.144 & 0.933 \\
\hline & Chlorhexidine & 1.4 & 0.5 & & 1.56 & 0.507 & & & \\
\hline & Herbal & 1.64 & 0.49 & & 1.6 & 0.5 & & & \\
\hline & Xylitol & 1.52 & 0.51 & & 1.6 & 0.5 & & & \\
\hline \multirow[t]{4}{*}{3 Months } & Fluoride & 1.28 & 0.458 & 2.279 & 0.084 & 1.44 & 0.507 & 0.351 & 0.789 \\
\hline & Chlorhexidine & 1.24 & 0.436 & & 1.4 & 0.5 & & & \\
\hline & Herbal & 1.56 & 0.507 & & 1.52 & 0.51 & & & \\
\hline & Xylitol & 1.4 & 0.5 & & 1.52 & 0.51 & & & \\
\hline \multirow[t]{4}{*}{6 Months } & Fluoride & 1.12 & 0.332 & 2.254 & 0.087 & 1.24 & 0.436 & 1.333 & 0.268 \\
\hline & Chlorhexidine & 1.16 & 0.374 & & 1.28 & 0.458 & & & \\
\hline & Herbal & 1.4 & 0.5 & & 1.4 & 0.5 & & & \\
\hline & Xylitol & 1.28 & 0.458 & & 1.48 & 0.51 & & & \\
\hline
\end{tabular}

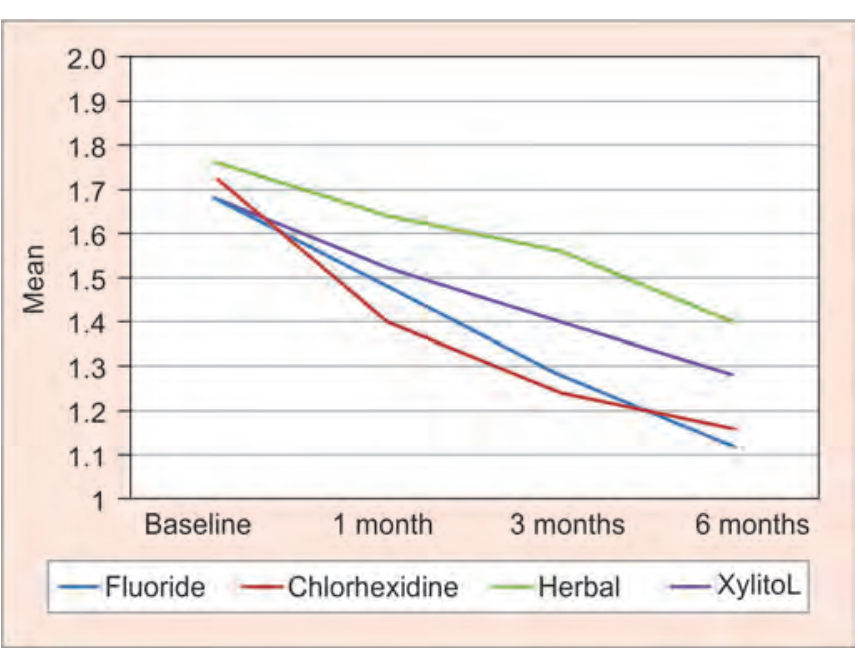

Graph 3: Intergroup comparison of S. mutans at different time periods

found. In group II while comparing the baseline with 3 to 6 months, the mean difference was 0.48 and 0.56 respectively which showed a statistically significant difference. For all the remaining time intervals in the group II, no statistically significant difference was found. On comparing group III, no statistically significant difference was found at any time interval. During intergroup comparison, group II was found to be more significant as the mean value was least followed by groups I, IV, and III. On intergroup comparison of $L B$ levels, the mean difference of baseline values with 6 months (0.48) in the fluoride group showed a statistically significant difference. In CHX group, on comparing the baseline with 3 to 6 months, the mean difference was found to be 0.40 and 0.52 respectively. For all the remaining time periods in $\mathrm{CHX}$, xylitol, and herbal group, no statistically significant difference was found.

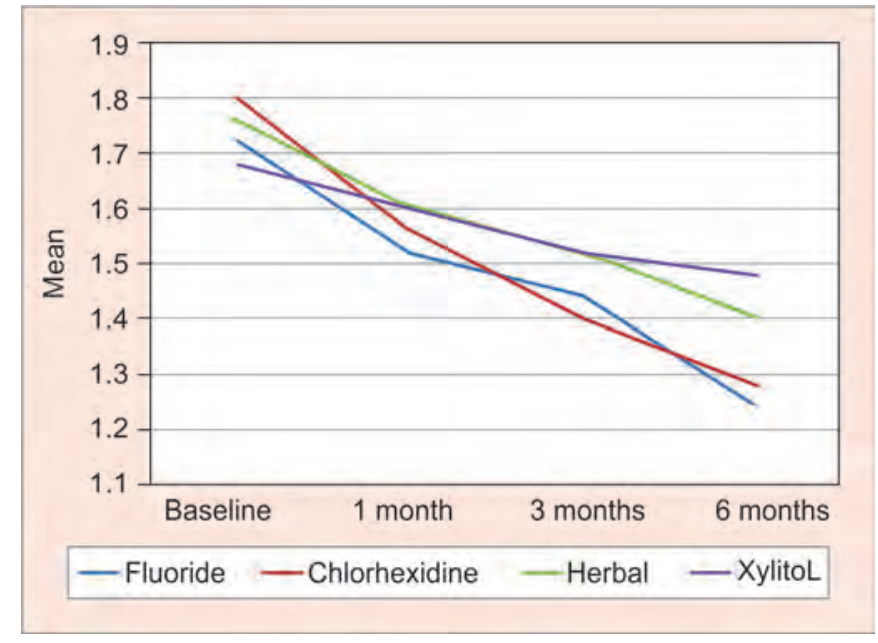

Graph 4: Intergroup comparison of $L B$ at different time periods

\section{DISCUSSION}

Caries occurs through a complex interaction over time between acid-producing bacteria, fermentable carbohydrate, teeth, and saliva. ${ }^{4}$ The acids that dissolve the dental hard tissues are synthesized by bacteria that are commensals of oral cavity. Therefore, an antibacterial approach to manage caries is a key advancement in the modern noninvasive mode of caries management.

Saliva was selected as a parameter for caries risk assessment as it can provide information on the component cause for the caries process and saliva can be collected noninvasively. ${ }^{10}$ Presence of $S$. mutans and $L B$ can be taken as indicator of a cariogenic environment and as indicator of sugar-induced biofilm stress.

The four antimicrobial agents used in this study were fluoride, CHX, herbal, and xylitol containing toothpastes and mouthwashes. Fluoride is the most commonly used 
antimicrobial agent against caries prevention. It facilitates reprecipitation of dissolved calcium and phosphate ions on the remaining crystals. ${ }^{11}$ Chlorhexidine is a cationic biguanide with a broad-spectrum antimicrobial action. The natural phytochemicals offer an effective alternative to antibiotics and represent a promising approach in prevention and management for dental caries. Xylitol is a sugar alcohol that hampers bacterial metabolism. ${ }^{12}$

Caries risk test kit was used in this study to evaluate the microbial count of $S$. mutans and LB. This method is easy, simple, valid and has been shown to be as accurate and reliable as the conventional culturing techniques. ${ }^{13}$ These tests can be undertaken at chair side within a short timeframe, and no special apparatus or techniques are required. ${ }^{10}$

Intragroup comparison of $S$. mutans at different time periods demonstrated that fluoride showed significant reduction in microbial count among baseline and at a time periods of 1, 3, and 6 months. Könönen et $\mathrm{al}^{14}$ performed a systematic review to evaluate the caries prophylactic effect of locally applied fluoride compounds. The results showed that the daily use of fluoride toothpaste forms the foundation of caries control process. Hausen ${ }^{15}$ established that fluoride inhibits demineralization which facilitates reprecipitation of dissolved calcium and phosphate ions on the remaining crystals. When the $\mathrm{pH}$ is higher than 5.5, fluoride will facilitate remineralization, promoting lesion arrest and enhancing repair.

During intragroup comparison of CHX and xylitol, the mean values were 1.16 and 1.28 respectively. The results are in accordance with the results of study by Tweetman ${ }^{16}$ who verified that twice daily usage of $\mathrm{CHX}$ causes significant reduction in $S$. mutans count which is evident at 1 month application. A study done by Milgrom et $\mathrm{al}^{17}$ evaluated the effect of $S$. mutans on xylitol chewing gum. The results showed that 3 weeks of xylitol chewing gum reduces the levels of $S$. mutans in saliva. Herbal toothpaste and mouthwash did not show significant reduction in microbial count for any time intervals. AbdElRahman et $\mathrm{l}^{18}$ evaluated the antimicrobial effects of miswak extracts on oral pathogens. The results showed that miswak has a relatively low antimicrobial activity against $S$. mutans.

On intergroup comparison of $S$. mutans with different agents, fluoride and CHX groups showed significant reduction in $S$. mutans count at the interval of baseline to 3 months and baseline to 6 months. Based on the result obtained by Kaneko et al, ${ }^{19}$ long-term use of NaF contributed to the reduction of salivary S. mutans in school children. The result from this study showed the tendency for sodium fluoride to inhibit $S$. mutans in saliva. Xylitol shows reduction in $S$. mutans count at a time period of 6 months. It is in accordance with a study by Campus et $\mathrm{al}^{20}$ who reported a reduction of salivary $S$. mutans count at 6 months intervention. This explains the need for longterm usage of xylitol for caries prevention.

During intragroup comparison of $L B$ at different time periods, CHX showed significant reduction in microbial count followed by fluoride. Xylitol and herbal did not show any significant reduction. This result is contradictory to a study conducted by Emilson, ${ }^{21}$ which showed that with the use of $\mathrm{CHX}$, minimal effect was seen on $L B$ growth. Herbal products did not reduce $L B$ count significantly. This was in accordance with a study done by Akhtar et $\mathrm{al}^{22}$ on the antibacterial effect of miswak in vitro on five different microbes. Results showed that $S$. mutans was less susceptible and $L B$ being least susceptible. Xylitol did not show significant reduction in microbial count for any time intervals.

Fluoride and CHX were effective in reducing $L B$ count when it was used for 6 months. Herbal and xylitol groups did not show any significant reduction in $L B$ at any time period.

\section{CONCLUSION}

Within the limitation of the present study, it can be concluded that fluoride showed a significant reduction in $S$. mutans count after a time period of 1,3 , and 6 months. A significant reduction in $L B$ count was observed in 3 to 6 months. Chlorhexidine showed a significant reduction in S. mutans and $L B$ count after a time period of 3 to 6 months. Herbal group did not show a significant reduction in $S$. mutans and LB count. Xylitol showed a significant reduction in $S$. mutans count after a time period of 6 months but not after 1 to 3 months.

\section{REFERENCES}

1. Twetman S. Treatment protocols: Non fluoride management of the caries disease process and available diagnostics. Dent Clin North Am 2010 Jul;54(3):527-540.

2. Loesche J. Role of Streptococcus mutans in dental decay. Microbiol Rev 1986 Dec;50(4):353-379.

3. Takahashi N, Nyvad B. The role of bacteria in the caries process: Ecological perspectives. J Dent Res 2011 Mar;90(3):294-303.

4. Featherstone J. The science and practice of caries prevention. J Am Dent Assoc 2000 Jul;131(7):887-899.

5. Marsh D. Are dental diseases examples of ecological catastrophes? Microbiol 2003 Feb;149(2):279-294.

6. Gold J. The role of chlorhexidine in caries prevention. Oper Dent 2008 Nov-Dec;33(6):710-716.

7. Singh J, Kumar A, Budhiraja S, Hooda A. Ethnomedicine: Use in dental caries. Braz J Oral Sci 2007 Apr-Jun;6(21):1308-1312.

8. Hildebrandt G, Sparks B. Maintaining mutans streptococci suppression: with xylitol chewing gum. J Am Dent Assoc 2000 Jul;131(7):909-916.

9. Featherstone J. Caries risk assessment in practice for age 6 through adults. J Calif Dent Assoc 2007 Oct;35(10):703-707.

10. Walsh L, Tsang A. Chairside testing for cariogenic bacteria: current concepts and clinical strategies. J Min Interven Dent 2008 Jul;1(2):126-147. 
11. Srinivasan M, Schimmel M. High-fluoride toothpaste: a multicenter randomized controlled trial in adults. Community Dent Oral Epidemiol 2014 Aug;42(4):333-340.

12. Arunakal M, Boonyaanit T, Yuwadee A. Efficacy of xylitol and fluoride mouthrinses on salivary mutans streptococci. Asian Pac J Trop Biomed 2011 Dec;1(6):488-490.

13. Featherstone J. The caries balance: the basis for caries management by risk assessment. Oral Health Prev Dent 2004;2(1): 259-264.

14. Könönen E. Development of oral bacterial flora in young children. Ann Med 2000 Mar;32(2):107-112.

15. Hausen H. Benefits of topical fluorides firmly established. Evid Based Dent 2004;5(2):36-37.

16. Tweetman S. Mutans streptococci suppression by chlorhexidine gel in toddlers. Am J Dent 1999 Apr;12(2):89-91.

17. Milgrom $P$, Robert M, Rothen M. Mutans streptococci dose response to xylitol chewing gum. J Dent Res 2006 Feb;85(2): 177-181.
18. AbdElRahman HF, Skaug N, Francis GW. In vitro antimicrobial effect of crude miswak extract on oral pathogen. Saudi Dent J 2002 Jan-Apr;14(1):26-32.

19. Kaneko N, Yoshihara A, Ida H, Nomura Y, Imai S, Nisizawa T, Sakuma S, Hanada N, Miyazaki H. Influence of a fluoride mouthrinse on mutans streptococci in school children. Caries Res 2006;40(6):501-507.

20. Campus G, Cagetti G, Sacco G, Solinas G, Mastroberardino S, Lingstrom P. Six months of daily high-dose xylitol in highrisk school children: a randomized clinical trial on plaque $\mathrm{pH}$ and salivary mutans streptococci. Caries Res 2009 Dec;43(6): 455-461.

21. Emilson G. Potential efficiency of chlorhexidine against mutans streptococci and human dental caries. J Dent Res 1994 Mar;73(3):628-629.

22. Akhtar J, Siddique KM, Bi S, Mujeeb M. A review on phytochemical and pharmacological investigations of miswak. J Pharm Bioallied Sci 2011 Jan-Mar;3(1):113-117. 